\title{
BRDOKHTSEN
}

NATIONAL LABORATORY

BNL-79152-2007-CP

\section{Coupling Impedance of CESR- B RF Cavity for the NSLS-II Storage Ring}

\author{
A. Blednykh, S. Krinsky and J. Rose \\ NSLS-II, Brookhaven National Lab \\ Presented at the 22nd Particle Accelerator Conference \\ Alburquerque, New Mexico \\ June 25-29, 2007
}

June 2007

\author{
National Synchrotron Light Source-II \\ Brookhaven National Laboratory \\ P.O. Box 5000 \\ Upton, NY 11973-5000 \\ www.bnl.gov
}

\begin{abstract}
Notice: This manuscript has been authored by employees of Brookhaven Science Associates, LLC under Contract No. DE-AC02-98CH10886 with the U.S. Department of Energy. The publisher by accepting the manuscript for publication acknowledges that the United States Government retains a non-exclusive, paid-up, irrevocable, world-wide license to publish or reproduce the published form of this manuscript, or allow others to do so, for United States Government purposes.
\end{abstract}




\section{DISCLAIMER}

This report was prepared as an account of work sponsored by an agency of the United States Government. Neither the United States Government nor any agency thereof, nor any of their employees, nor any of their contractors, subcontractors, or their employees, makes any warranty, express or implied, or assumes any legal liability or responsibility for the accuracy, completeness, or any third party's use or the results of such use of any information, apparatus, product, or process disclosed, or represents that its use would not infringe privately owned rights. Reference herein to any specific commercial product, process, or service by trade name, trademark, manufacturer, or otherwise, does not necessarily constitute or imply its endorsement, recommendation, or favoring by the United States Government or any agency thereof or its contractors or subcontractors. The views and opinions of authors expressed herein do not necessarily state or reflect those of the United States Government or any agency thereof. 


\title{
COUPLING IMPEDANCE OF CESR-B RF CAVITY FOR THE NSLS-II STORAGE RING*
}

\author{
Alexei Blednykh", Samuel Krinsky, Jim Rose \\ BNL, NSLS, Upton, NY, 11973-5000, U.S.A.
}

\begin{abstract}
CESR-B type superconducting cavities are under consideration for acceleration of the electron beam in the $3 \mathrm{GeV}$ NSLS-II storage ring. In this paper we present detailed investigation of longitudinal and transverse impedance of CESR-B cavity and transitions. Ferrite material is included in impedance analysis. Its effect on short range wakepotential has been studied using GdfidL code. The summary results of loss factors and kick factors are presented for a $3 \mathrm{~mm}$ rms bunch length.
\end{abstract}

\section{INTRODUCTION}

CESR-B [1] type superconducting (SC) cavities are considered as a top choice for acceleration of the electron beam in the $3 \mathrm{GeV}$ NSLS-II storage ring. Employing the full set of damping wigglers in the ring, $1 \mathrm{MW}$ power will be required [2]. Due to RF power limiting per coupler, $\sim 270 \mathrm{~kW}$ [3], four $500 \mathrm{MHz}$ CESR-B main SCRF cavities are planned to be fitted in two 8 meter straight sections. To improve the Touschek lifetime, two passive $1500 \mathrm{MHz}$ harmonic SCRF cavities (scaled CESR-B cavity [4] or Super3HC cavity [5]) will be used for bunch lengthening. The layout of two CESR-B cavities plus a single Super3HC harmonic cavity in a single straight is shown in Figure 1.

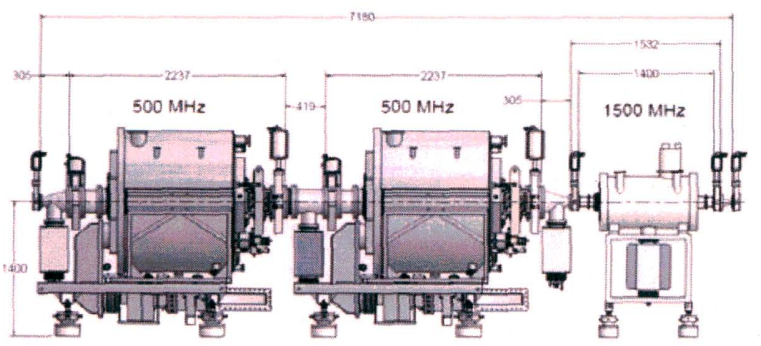

Figure 1: Layout of two $500 \mathrm{MHz}$ cavities plus one 1500 $\mathrm{MHz}$ Landau cavity in a single straight.

The complicated nature of the RF cavities requires significant computational resources to establish the longitudinal and transverse impedances for the whole assembly. Each cavity has a special fluted beam pipe for Higher Order Modes (HOMs) coupling. Ferrite liners are located in the beam pipe on both sides of each cavity for HOMs damping. There are smooth transitions between main and harmonic cavities and regular beam pipe vacuum chamber. In order to avoid computational complications, the coupling impedance in the whole assembly can be estimated as a sum the impedance of

*Work supported by DOE contract DE-AC02-98CH10886.

\#blednykh@bnl.gov cavities and transitions. A similar analysis was carried out by S. Belomestnykh [6] for CESR-B assembly for bunch lengths $\sigma_{\mathrm{s}} \geq 10 \mathrm{~mm}$. This approach allows us to verify computed data with analytical results using simplified geometries.

We would like to point out that the transitions between RF cavities and regular vacuum chamber are major contributors to the longitudinal and transverse broad-band coupling impedance. The kick factor of the cavity itself becomes smaller for shorter bunch $\left(\kappa_{\mathrm{y}} \sim \sigma^{1 / 2}\right)$ in agreement with analytical expression of Bane and Sands [7] and Novokhatsky [8] for a pill-box cavity. The loss factor of the cavity is inversely proportional to the bunch length $\left(\kappa_{\text {loss }} \sim \sigma^{-1 / 2}\right.$ ) but it is much smaller than the loss factor of the transitions for a $3 \mathrm{~mm}$ rms bunch length (see results in Table 1 and 2).

\section{CESR-B MAIN RF CAVITY}

The $500 \mathrm{MHz}$ main RF cavity with the attached round beam pipe of radius $120 \mathrm{~mm}$ on one side and the fluted beam pipe for HOMs coupling on the other is shown in Fig. 2. For simplicity the RF coupler was not included in these computations. The coupling impedance of the rectangular slot in the round beam pipe, which will be used for matching of the input power to the cavity, can be estimated analytically or can be computed separately and added to the total impedance of the cavity.

One-quarter of the structure with magnetic boundary conditions is used for the numerical computations of the longitudinal wakepotential and one-half of the structure with magnetic boundary condition in x-plane is used for the numerical computations of the transverse wakepotential using GdfidL code [9].

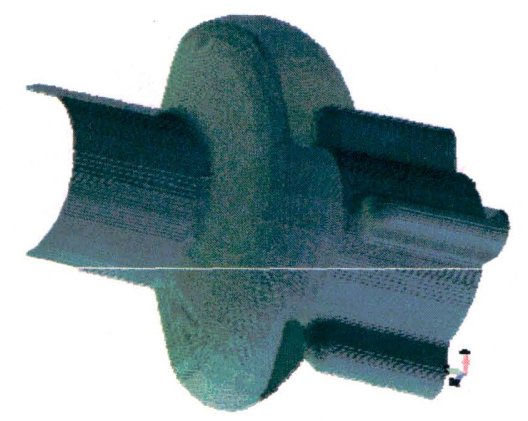

Figure 2: One-half of the CESR-B RF cavity. 3D GdfidL model.

The longitudinal monopole and transverse dipole wakepotentials are computed for a $3 \mathrm{~mm}$ rms bunch length. The short-range wakepotentials for the CESR-B main cavity are shown in Fig. 3. 

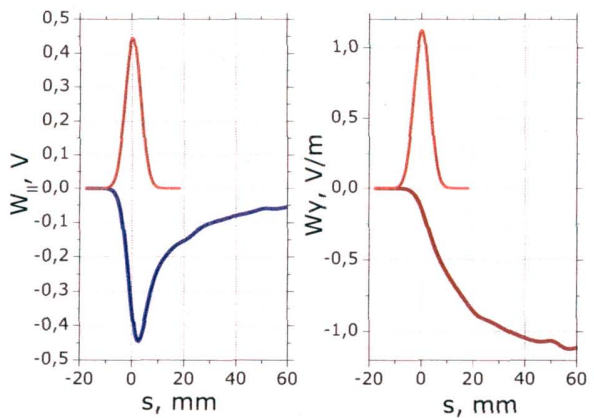

Figure 3: Longitudinal and transverse short range wakepotentials for CESR-B main RF cavity $\left(\sigma_{s}=3 \mathrm{~mm}\right)$.

The loss factor has been calculated by integrating the convolution of the dipole-wakepotential with the bunch distribution. The dependence of the loss factor (blue points) and kick factor (green crosses) on bunch length for $500 \mathrm{MHz}$ CESR-B cavity is shown in Figure 4.

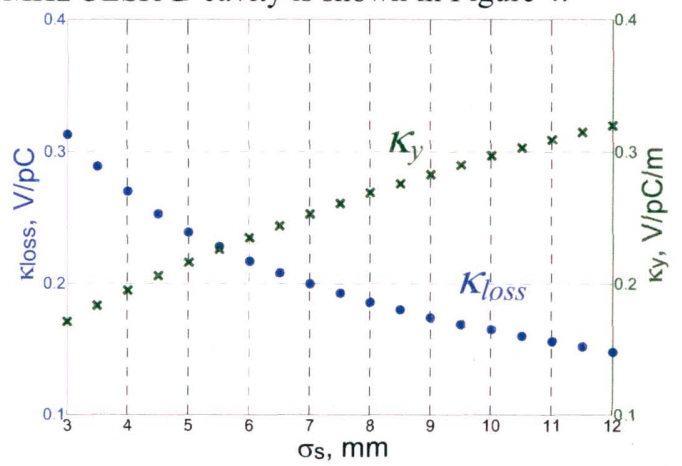

Figure 4: Loss factor and kick factor versus bunch length.

The following Table 1 compares results of the loss factor and the kick factor for $500 \mathrm{MHz}$ CESR-B RF cavity and main cavity transition for a $3 \mathrm{~mm}$ rms bunch length. Main cavity transition refers to one tapered transition between the regular elliptic vacuum chamber and the round beam pipe of the main cavity (the taper angle is $\sim 20^{\circ}$ ) and one tapered transition between the round main cavity beam pipe and the round harmonic cavity beam pipe (the taper angle is $\sim 15^{\circ}$ ). Contribution to the longitudinal impedance in terms of the loss factor of two $300 \mathrm{~mm}$ tapers with two different angles is significant $\left(\kappa_{\text {loss }}=3 \mathrm{~V} / \mathrm{pC}\right)$. This value is comparable with the values for $720 \mathrm{~m}$ aluminum resistive wall $\left(\kappa_{\text {loss }}=4 \mathrm{~V} / \mathrm{pC}\right)$ and for 270 BPMs $\left(\sum \kappa_{\text {loss }}=5.4 \mathrm{~V} / \mathrm{pC}\right)$ from impedance table for NSLS-II $[10,11]$. Cavity itself gives a smaller contribution to the longitudinal impedance than the tapered transition.

Table 1: Loss factor and kick factors $\left(\sigma_{s}=3 \mathrm{~mm}\right)$ for $500 \mathrm{MHz}$ main CESR-B cavity and main cavity transition.

\begin{tabular}{|l|c|c|c|}
\hline & $\begin{array}{c}\kappa_{\text {loss }}, \\
\mathbf{V} / \mathbf{p C}\end{array}$ & $\begin{array}{c}\kappa_{x}, \\
\mathbf{V} / \mathbf{p C} / \mathbf{m}\end{array}$ & $\begin{array}{c}\boldsymbol{\kappa}_{y}, \\
\mathbf{V} / \mathbf{p C} / \mathbf{m}\end{array}$ \\
\hline Main cavity & 0.31 & 0.17 & 0.17 \\
\hline Main transition & 3 & 18 & 36.4 \\
\hline
\end{tabular}

\section{HARMONIC RF CAVITY}

To increase the Touschek lifetime and to reduce the effect of intrabeam scattering on the emittance, thirdharmonic Landau cavities are planned to be installed in the NSLS-II storage ring. Bunch lengthening due to harmonic cavity will be useful also in raising the longitudinal microwave instability threshold. To estimate contribution of the harmonic cavity to the total impedance of the ring we are using a scaled model of the CESR-B main cavity at frequency $1500 \mathrm{MHz}$.

Table 2 contains the loss factor and kick factors for $1500 \mathrm{MHz}$ CESR-B harmonic RF cavity. The loss factor of the harmonic cavity is increased by a factor of 0.58 $\left(\kappa_{\text {loss }} \propto \sqrt{g} / a\right)$ due to scaling of the cavity dimensions by a factor of 3 . The beam pipe radius of the harmonic cavity is $40 \mathrm{~mm}$. An additional tapered transition is required between the round beam pipe of the harmonic cavity and the elliptic vacuum chamber of the ring. The taper length is chosen to be $100 \mathrm{~mm}\left(\sim 15^{\circ}\right.$ angle $)$. Contribution of the entire transitions per straight including the main cavity transition and one taper of the harmonic cavity transition is given in Table 2. For simplicity, the length of straight pipes between tapers is taken to be $300 \mathrm{~mm}$ rather than $4.8 \mathrm{~m}$ and $1.5 \mathrm{~m}$ for the main cavity straight-pipe and for the harmonic cavity straight-pipe respectively.

Table 2: The summary results of the loss factor and the kick factor $\left(\sigma_{s}=3 \mathrm{~mm}\right)$ for the CESR-B harmonic cavity and the entire transitions per straight.

\begin{tabular}{|l|c|c|c|}
\hline & $\begin{array}{c}\boldsymbol{\kappa}_{\text {loss }}, \\
\mathbf{V} / \mathbf{p C}\end{array}$ & $\begin{array}{c}\boldsymbol{\kappa}_{x}, \\
\mathbf{V} / \mathbf{p C} / \mathbf{m}\end{array}$ & $\begin{array}{c}\boldsymbol{\kappa}_{y}, \\
\mathbf{V} / \mathbf{p C} / \mathbf{m}\end{array}$ \\
\hline Harmonic RF cavity & 0.52 & 2.6 & 2.6 \\
\hline $\begin{array}{l}\text { Cavity transition per } \\
\text { straight }\end{array}$ & 3.5 & 25.4 & 57 \\
\hline
\end{tabular}

\section{EFFECT OF FERRITE ON SHORT RANGE WAKEPOTENTIAL}

The ferrite lined pill-box cavity was analyzed with the program CLANS and compared with analytical data [12]. Pill-box cavity dimensions are $124 \mathrm{~mm}$ radius, $65 \mathrm{~m}$ length with $5 \mathrm{~mm}$ thick ferrite tile on outer radius (from $119 \mathrm{~mm}$ to $124 \mathrm{~mm}$, full length). The ferrite properties (for testing code) were taken to be $\varepsilon^{\prime}=12, \mu^{\prime}=2$. Results for the $\mathrm{E}_{010^{-}}$ mode are given in the Table 3 .

Table 3: Quality factors and frequencies of the $\mathrm{E}_{010^{-}}$-mode versus $\mu^{\prime \prime}$ for a pill-box cavity model.

\begin{tabular}{|c|c|c|c|c|}
\hline \multirow{2}{*}{$\mu^{\prime \prime}$} & \multicolumn{2}{|c|}{ CLANS } & \multicolumn{2}{c|}{ Analytic [12] } \\
\cline { 2 - 5 } & $f_{\mathrm{E} 010}$ & $\mathrm{Q}_{\mathrm{E} 010}$ & $f_{\mathrm{E} 010}$ & $\mathrm{Q}_{\mathrm{E} 010}$ \\
\hline 2 & 881 & 5.42 & 880.9 & 5.42 \\
\hline 5 & 851 & 1.90 & 851.0 & 1.90 \\
\hline
\end{tabular}


We compared GdfidL data (kernel-51n), using the same pill-box cavity model as in frequency domain, with analytical results. It was found that GdfidL finds the shape of the electric and magnetic fields in agreement with the analytic result for the two modes considered [12]. The quality factors are in reasonable agreement. However, the mode frequencies in the presence of the ferrite show not correct result. Further investigation is needed, but we believe GdfidL results with ferrite will be accurate for the short-range wakepotential.

To estimate ferrite effect on short-range wakepotential (broad-band impedance) we chose a simplified model. It is a symmetric tapered structure as shown in Figure 5. The RF cavity shape is excluded from analysis as its contribution to the longitudinal broad-band impedance is much smaller $\left(\kappa_{\text {loss }}=0.31 \mathrm{~V} / \mathrm{pC}\right)$ than contribution of the tapered transition $\left(\kappa_{\text {loss }}=3 \mathrm{~V} / \mathrm{pC}\right)$.

The regular beam pipe for the NSLS-II storage ring has an elliptical cross section of the full width $78 \mathrm{~mm}$ and full height of $25 \mathrm{~mm}$ [13]. The cutoff frequency of the lowest longitudinal mode for the given cross section is $\sim 7 \mathrm{GHz}$. In GdfidL the material parameters such as the electric conductivity, magnetic conductivity, the relative permittivity and the relative permeability are modeled frequency independent. Ferrite parameters were specified for the frequency $2.8 \mathrm{GHz}$.

The longitudinal short-range wakepotential is plotted in Figure 5 for three different cases; empty structure, with one lined ferrite ring and with two lined ferrite rings. It can be seen that the shape of the short-range wakepotential does not change. The three curves lie on top of one another inside the bunch. This means that the loss factor depends only on the geometric impedance and ferrite rings inside do not affect the short range wakepotential.

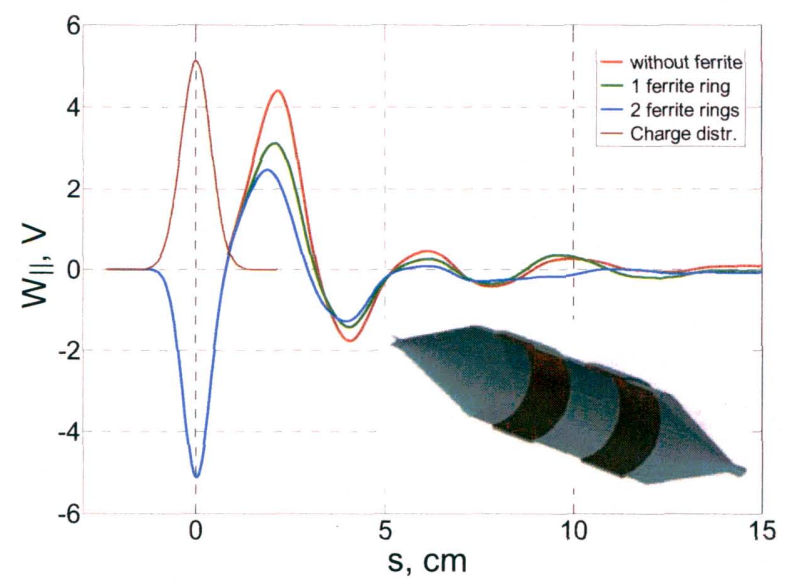

Figure 5: Longitudinal short range wakepotential for the tapered structure. Red curve is no ferrite rings inside the geometry. Light green curve is one ferrite ring inside. Blue curve is two ferrite rings lined inside.

\section{CONCLUSION}

Impedance analysis of CESR-B type superconducting cavities shows that tapered cavity transitions are major contributors to the longitudinal broad-band impedance. The considered length of transitions is acceptable for NSLS-II as a whole assembly can be fitted in $8 \mathrm{~m}$ straight section. The total loss factor for two considered $7.2 \mathrm{~m} \mathrm{RF}$ straight sections is $10.3 \mathrm{~V} / \mathrm{pC}$. It is about one-half of the total loss factor for the NSLS-II storage ring. To minimize transition impedance, taper lengths between RF cavities per straight will be lengthened to the extent allowed by the available space.

Ferrite rings on both sides of the RF cavities for HOM damping (narrow-band impedance) does not affect the short-range wakepotential (broad-band impedance).

\section{ACKNOWLEDGEMENT}

We thank $H$. Padamsee for providing drawings of CESR-B assembly for NSLS-II and S. Belomestnykh for useful discussions about his experience with CESR-B cavities. Thanks to $\mathrm{W}$. Bruns for his help and guiding us in GdfidL.

\section{REFERENCES}

[1] H. Padamsee et al. "Accelerating Cavity Development for the Cornell B-Factory, CESR-B”, PAC1991, May 6-9, Sun Francisco, pp786.

[2] J. Rose et al., "Conceptual Design of the NSLS-II RF Systems", PAC2007.

[3] S. Belomestnykh and H. Padamsee, "Performance of the CESR Superconducting RF System and Future Plans," SRF2001, KEK, Japan, 2001.

[4] P. vom Stein et al., "A Superconducting Landau Accelerator Module for BESSY II", PAC2001, Chicago, pp. 1175-1176.

[5] M. Svandrlik et al., "The Super-3HC Project", EPAC200, pp. 2052-2054.

[6] S. Belomestnykh, "On the BB1 Cryomodule Loss Factor Calculations," Tech None SRF 990714-08, Cornell University, Ithaca 1999.

[7] K. Bane and M. Sands, "Wakefields of very short bunches in an accelerating cavity," SLAC-PUB-4441, November 1987.

[8] A.V. Novokhatski, "On the estimation of the wake potential for an ultrarelativistic charge in an accelerating structure," Preprint INP 88-39, Institute of Nuclear Physics, Novosibirsk, 1988.

[9] W. Bruns, GdfidL code, http://www.gdfidl.de

[10] A. Blednykh and S. Krinsky, "Preliminary Impedance Budget for NSLS-II Storage Ring", PAC2007.

[11] Conceptual design report for NSLS-II p. 780, http://www.nsls2.bnl.gov.

[12] H. Hahn, A. Blednykh, L. Hammons, D. Kayran and J. Rose, "Ferrite Lined Pillbox Cavity", Tech None CA/AP/269, February 2007.

[13] A. Blednykh and S. Krinsky, "Coupling impedance of electron beam vacuum chambers for the NSLS-II storage ring", PAC2007. 